\title{
Assessment of the Satisfaction of Customers Using Mobifone Mobile Service in Ho Chi Minh City
}

\author{
Dr. Phan Quan Viet \\ Faculty of Commerce \& Business Administration, Van Lang University, Viet Nam
}

Received: January 15, 2019 Accepted: January 29, 2019 Published: March 4, 2019

doi:10.5296/ber.v9i1.14450

URL: https://doi.org/10.5296/ber.v9i1.14450

\begin{abstract}
In recent years, the telecommunications service market has developed rapidly and strongly, contributed to help the telecommunications market become more competitive, supplied a variety of services with reasonable prices, and brought benefits for users. Up to now, the market share of the mobile market in Ho Chi Minh City in general and Ho Chi Minh City in particular is being divided to 4 service suppliers: Mobifone, VinaPhone, Viettel, Vietnamobile. From January 08, 2018, the network operators started a new war to gain market share since the regulation on the conversion of the terrestrial mobile telecommunications network with unchanged number of the Ministry of Information and Communication comes into effect. Network operators must compete for service quality, if customers are not satisfied, they will switch to another network operator and remain their numbers. This is good for customers but poses a big challenge for network operators like Mobifone.

A research of assessment of the satisfaction of customers using Mobifone mobile service in Ho Chi Minh City aims to measure the influence of some factors to the satisfaction of customers who are living and working in Ho Chi Minh City. Since then, solutions are given to help Mobifone change its direction to attract subscribers by increasing service quality, thereby improving customers' satisfaction.
\end{abstract}

Keywords: Satisfaction, Service, Telecommunications

\section{Introduction}

Customers' satisfaction with products - services is a vital issue for every business. In today's context, technological advancements, mobile telecommunications services today have become popular and indispensable for everyone in daily life. Especially, when there are quite a lot of competitors, the research on the service quality supplied to customers of each business is extremely necessary to retain existing customers as well as entice potential customers. 
On November 23, 2017, the Ministry of Information and Communications promulgated Circular No. 35/2017/TT-BTTTT which stipulates the conversion of the terrestrial mobile telecommunication network with unchanged number. The conversion of the terrestrial mobile telecommunication network with unchanged number (converting network) means the mobile subscriber of this terrestrial mobile information service supplier becomes a mobile subscriber of other terrestrial mobile information service supplier and retains the number (including network code and subscriber number). Telecommunications businesses equally provide a service of network conversion regardless of mobile subscribers. This Circular takes effect from January 08, 2018. Since then, the network operators start to fight for market share. Network operators must compete for service quality, if customers are not satisfied, they will switch to another network operator and remain their numbers. This is good for customers but poses a big challenge for network operators like Mobifone because according to Mobifone's representative, the risk of losing market share, especially the market share of loyal customers, is entirely possible. For example, customers switch to networks with better service quality, especially better prices and prepaid subscribers are considered to be the easiest to switch networks. It can be seen that the deployment of network conversion service with unchanged number is an effective tool to promote competition, implemented by many countries around the world. At that time, the work of the service quality assurance will be very important. Therefore, the key plan of the network operators in 2018 is to keep and develop customers during the period of converting network and remaning number. No network operator wants their customers to switch to and use another network operator's services.

From this reality, what should Mobifone do to maintain its market share in Ho Chi Minh City and develop in the future? With these forecasts, Mobifone must change its direction to attract subscribers by increasing service quality thereby improving customers' satisfaction. But how to know what customers care about? And which factors affect that satisfaction?

\section{Research Method}

Sample size and sampling method: The study was conducted with 37 observed variables and the sample size was 300. Sampling method: probabilityless by convenient sampling. Mobifone mobile subscribers regardless of age and occupation are easily accessible at agencies, units or living in wards / communes of Ho Chi Minh City.

Research using the following analytical techniques: Descriptive statistics, verification of the reliability of scales, factor analysis, analysis of correlation coefficients, assessment of differences between grouping properties Depend on the dependent variable by Independent Samples T-Test, Anova analysis and multiple regression analysis with model verification techniques.

\section{Research Model}

According to the available studies, the analysis mentioned in section 2.3 chapter 2 , the author proposes a research model for "Assessment of the satisfaction of customers using Mobifone mobile service in Ho Chi Minh City." as Figure 1 below. 


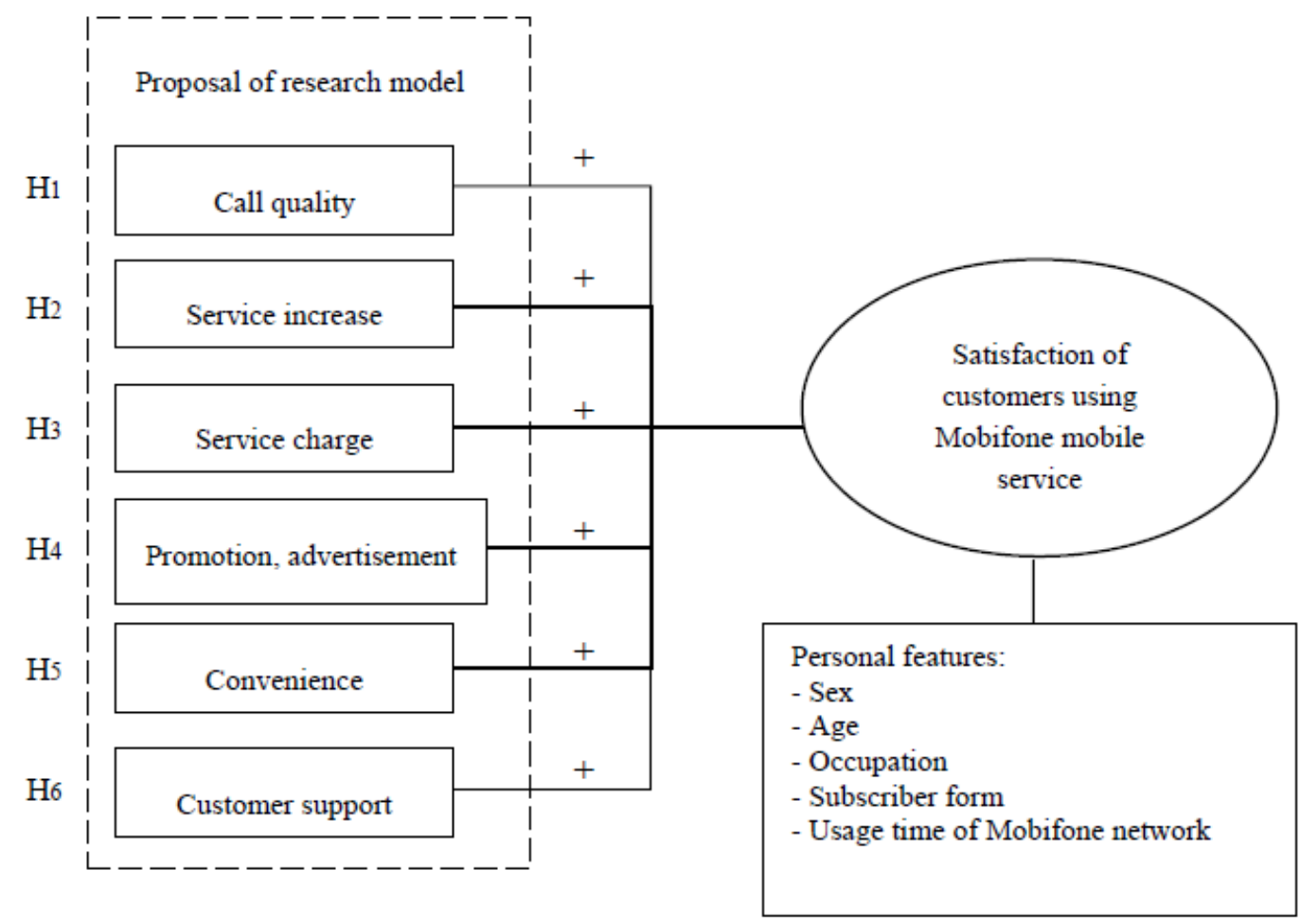

Figure 1. Research model for Assessment of the satisfaction of customers using Mobifone mobile service in Ho Chi Minh City

\section{Research Results}

\subsection{Assessment of Reliability of Scale Using Cronbach's Alpha Coefficient}

After collecting official data, checking and entering data, reliability analysis of scale using Cronbach's Alpha coefficient for 6 independent components is conducted. Results of reliability analysis of scale using Cronbach's Alpha coefficient are shown in Table 1.

Table 1. Cronbach's Alpha analysis results

\begin{tabular}{|c|l|c|c|}
\hline Symbol & \multicolumn{1}{|c|}{ Component } & Number of observed variables & Cronbach's Alpha coefficient \\
\hline CL & Call quality & 4 & 0.874 \\
\hline DV & Service increase & 4 & 0.805 \\
\hline GC & Service charge & 5 & 0.838 \\
\hline KM & Promotion, advertisement & 5 & 0.821 \\
\hline TT & Convenience & 5 & 0.825 \\
\hline KH & Customer support & 6 & 0.805 \\
\hline SHL & Satisfaction & 8 & 0.874 \\
\hline
\end{tabular}

(Source: Processing SPSS)

Through the analysis results in Table 1, Cronbach's Alpha coefficients of 6 independent components are $>0.8,01$ dependent component $>0.7$ and item-total correlation of variables is $>0.3$. Therefore, the scale is reliable and accepted to measure the satisfaction of customers 


\section{Macrothink}

Business and Economic Research

ISSN 2162-4860

2019, Vol. 9, No. 1

using Mobifone mobile service in Ho Chi Minh City. All 6 independent components and 29 variables in the scale are used by Exploratory Factor Analysis for the formal research

\subsection{Exploratory Factor Analysis for the Formal Research}

\subsubsection{Exploratory Factor Analysis for Independent Components}

According to Table 2. KMO coefficient reaches .768 (greater than .5) and Sig. value at the Barlett test reaches .000 (less than .05), eligible to conduct Exploratory Factor Analysis.

Table 2. KMO, Barlet test for independent variables

\begin{tabular}{|l|l|l|}
\hline Kaiser-Meyer-Olkin Measure of Sampling Adequacy. (KMO coefficient) & $\mathbf{. 7 6 8}$ \\
\hline Bartlett's Test of & Approximate Chi-square value & 3689.950 \\
\cline { 2 - 3 } Sphericity (Barlett test) & df & 406 \\
\cline { 2 - 3 } & Sig. & $\mathbf{. 0 0 0}$ \\
\hline
\end{tabular}

Source: SPSS data processing analysis

There are 6 components extracted (Total value or Eigenvalue is greater than 1) with the total variance explained is $61.351 \%>50 \%$ (satisfactory), meaning that these 6 components have explained $61.351 \%$ variable variance of data (Table 3 ).

Table 3. Total variance explained, formal EFA

\begin{tabular}{|c|c|c|c|c|c|c|c|c|c|}
\hline \multirow[b]{2}{*}{ 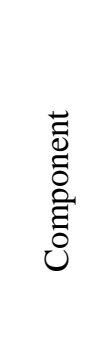 } & \multicolumn{3}{|c|}{ Initial Eigenvalues } & \multicolumn{3}{|c|}{$\begin{array}{c}\text { Extraction Sums of Squared } \\
\text { Loadings }\end{array}$} & \multicolumn{3}{|c|}{$\begin{array}{l}\text { Rotation Sums of Squared } \\
\text { Loadings }\end{array}$} \\
\hline & స్ㅠㅇ & 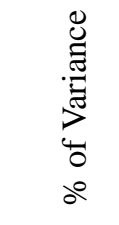 & $\begin{array}{l}\delta^{0} \\
\stackrel{0}{\Xi} \\
\stackrel{\Xi}{\Xi} \\
\stackrel{\Xi}{\Xi} \\
\Xi \\
\Xi\end{array}$ & 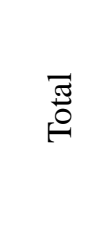 & 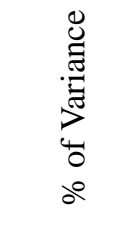 & 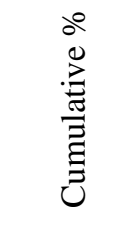 & సี & 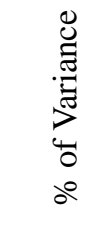 & 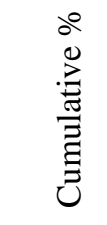 \\
\hline 1 & 4.708 & 16.234 & 16.234 & 4.708 & 16.234 & 16.234 & 3.127 & 10.781 & 10.781 \\
\hline 2 & 3.189 & 10.998 & 27.232 & 3.189 & 10.998 & 27.232 & 3.080 & 10.619 & 21.400 \\
\hline 3 & 3.019 & 10.409 & 37.640 & 3.019 & 10.409 & 37.640 & 3.019 & 10.409 & 31.810 \\
\hline 4 & 2.783 & 9.598 & 47.238 & 2.783 & 9.598 & 47.238 & 2.999 & 10.343 & 42.152 \\
\hline 5 & 2.217 & 7.643 & 54.881 & 2.217 & 7.643 & 54.881 & 2.970 & 10.242 & 52.394 \\
\hline 6 & 1.876 & 6.470 & 61.351 & 1.876 & 6.470 & 61.351 & 2.597 & 8.956 & 61.351 \\
\hline 7 & .975 & 3.363 & 64.714 & & & & & & \\
\hline
\end{tabular}

Source: SPSS data processing analysis

Rotated Component Matrix with Varimax rotation extracts 6 components with high factor loading on only a certain component and the variables have factor loading which is greater than 0.5 (satisfactory), the variables are classified into the initial official components are all in the same factor as the rotation component matrix result (Table 4). The scale results after the EFA are officially used to study, analyze, and assess in the next step. 
Table 4. Rotated Component Matrix of formal EFA

\begin{tabular}{|l|l|l|l|l|l|l|}
\hline & \multicolumn{3}{|l}{ Components } & \multicolumn{4}{l|}{} \\
\hline & 1 & 2 & 3 & 4 & 5 & 6 \\
\hline KH5 & .757 & & & & & \\
\hline KH3 & .734 & & & & & \\
\hline KH2 & .728 & & & & & \\
\hline KH4 & .688 & & & & & \\
\hline KH6 & .672 & & & & & \\
\hline KH1 & .637 & & & & & \\
\hline GC4 & & .853 & & & & \\
\hline GC2 & & .763 & & & & \\
\hline GC5 & & .759 & & & & \\
\hline GC3 & & .744 & & & & \\
\hline GC1 & & .703 & & & & \\
\hline KM2 & & & .815 & & & \\
\hline KM3 & & & .778 & & & \\
\hline KM4 & & & .771 & & & \\
\hline KM5 & & & .755 & & & \\
\hline KM1 & & & .694 & & & \\
\hline TT2 & & & & .785 & & \\
\hline TT1 & & & & .784 & & \\
\hline TT3 & & & & .768 & & \\
\hline TT4 & & & & .758 & & \\
\hline TT5 & & & & .711 & & \\
\hline CL1 & & & & & .881 & \\
\hline CL3 & & & & & .865 & \\
\hline CL2 & & & & & .836 & \\
\hline CL4 & & & & & .792 & \\
\hline DV4 & & & & & & .845 \\
\hline DV3 & & & & & & .833 \\
\hline DV1 & & & & & & .741 \\
\hline DV2 & & & & & & .703 \\
\hline
\end{tabular}

(Source: SPSS data processing analysis)

Table 4 shows the results of Rotated Component Matrix. There are 6 components extracted into 6 independent variables and named representing component according to Table 4.13. The number of components extracted is consistent with the initial components of the scale. Therefore, research concepts in this case achieve discriminant value.

- The EFA for dependent components

After the EFA for independent variables and extracting the last 6 components, we continue to analyze the components for "Satisfaction" as follows: 
KMO coefficient reaches .806 (greater than .5) and Sig. value at the Barlett test reaches .000 (less than .05) (Table 5), eligible to conduct exploratory factor analysis.

Table 5. KMO, Barlet test for dependent variable

\begin{tabular}{|l|l|l|}
\hline \multicolumn{2}{|l|}{ Kaiser-Meyer-Olkin Measure of Sampling Adequacy. } & .901 \\
\hline Bartlett's Test of Sphericity & Approx. Chi-Square & 988.650 \\
\cline { 2 - 3 } & df & 28 \\
\cline { 2 - 3 } & Sig. & .000 \\
\hline
\end{tabular}

(Source: SPSS data processing analysis)

There is one component extracted (with Total value or Eigenvalue greater than 1) with a total variance explained of $53.565 \%$ (greater than $50 \%$ ), consistent with the initial component concept (Table 6).

Table 6. Total Variance Explained, formal EFA

\begin{tabular}{|l|l|l|l|l|l|l|}
\hline \multicolumn{2}{|l|}{ Total Variance Explained } \\
\hline \multirow{2}{*}{ Component } & \multicolumn{2}{|l|}{ Initial Eigenvalues } & \multicolumn{3}{|c|}{ Extraction Sums of Squared Loadings } \\
\cline { 2 - 7 } & Total & $\%$ of Variance & Cumulative \% & Total & $\%$ of Variance & Cumulative \% \\
\hline 1 & 4.285 & 53.565 & 53.565 & 4.285 & 53.565 & 53.565 \\
\hline 2 & .735 & 9.188 & 62.754 & & & \\
\hline
\end{tabular}

(Source: SPSS data processing analysis)

Analysis results from tables 4,5 and 6 show that the dependent variable of the model is measured by 8 observed variables with good convergence. The EFA has grouped observed variables of satisfaction concept into a component. Observed variables SHL1, SHL2, SHL3, SHL4, SHL5, SHL6, SHL7, SHL8 with its factor loading according to Table 4.17 are greater than 0.5 ; Eigenvalue $=4.224>1, \mathrm{KMO}$ coefficient $=0.806$ and total variance explained $=$ $52.793>50 \%$ is satisfactory.

The formal quantitative study will derive the results extracted from the EFA for the dependent component of 8 initial satisfaction variables to gather a single variable using the MEAN instruction. The content of this gross variable is "Satisfaction level for Mobifone mobile service in Ho Chi Minh City", denoted as SHL. (Table 6)

\section{Conclusion}

The description of the sample information helps the author have an overview of the research sample according to 5 parameters: sex, age, occupation, usage time of Mobifone mobile network and form of mobile subscribers. The descriptive statistics also show that customers are satisfied with Mobifone mobile service in Ho Chi Minh City with the average value of all components which is greater than 3.00. The next step is to consider customers' expression of satisfaction in each aspect of Mobifone mobile service supply in Ho Chi Minh City.

On the basis of the survey results by questionnaires, assessment of the reliability of the scale with Cronbach alpha coefficient and Exploratory Factor Analysis are conducted. Then, the 
author uses multiple regression analysis in order to determine the importance of the independent variables involved in explaining the dependent variable, concurrently verify the proposed model and hypotheses.

The purpose of this study is to test the proposed theoretical model, measure the satisfaction of customers using Mobifone mobile service in Ho Chi Minh City.

Scale test by assessing Cronbach's Alpha reliability and Exploratory Factor Analysis with no observed variables still remains the model of 6 independent components and 29 observed variables. The EFA confirms the proposed initial research model with 6 reliable components in measuring customers' satisfaction when using the service. It is satisfaction with call quality, service increase, service charge, promotion, advertisement, convenience and customer support.

The results of Pearson linear correlation analysis show that 6 independent variables correlate with the dependent variable.

Linear regression analysis with 6 independent components and 1 dependent component is conducted that result leads to a linear regression equation with adjusted $\mathrm{R}^{2}=63.8 \%$, independent variables of multiple regression models have explained $63.8 \%$ of variation of the dependent variable SHL so it can be used for research. Component variable test (Student test) shows results of the independent comnponents affecting in the same direction to the dependent variable SHL. The entire model test (Fisher test) concludes that the independent variables of the multiple regression model explain in a meaningful way for the variation of the dependent variable SHL; or the linear regression model is built to be consistent with the existing and statistically significant data. In addition, other test steps show that the model has no first-order autocorrelation, no change of error variance phenomenon and no collinearity phenomenon.

The overall regression model is written in the form of:

$$
\mathrm{SHL}=0.252 \mathrm{KH}+0.314 \mathrm{GC}+0.259 \mathrm{KM}+0.238 \mathrm{TT}+0.187 \mathrm{CL}+0.300 \mathrm{DV}+\varepsilon
$$

A test of the difference between the attributes of customer grouping and customers' satisfaction by Independent-samples T-Test and one way ANOVA is conducted. The result shows no difference, means sex, age, occupation, form of mobile subscribers and customers' usage time of Mobifone network do not affect "Satisfaction of customers using Mobifone mobile service in Ho Chi Minh City". It means, when building the regression equation regardless of the above qualitative variables.

\section{References}

The Ministry of Information and Communications (2017). Circular No. 35/2017/TT-BTTTT dated November 23, 2017 which stipulates the conversion of the terrestrial mobile telecommunication network with unchanged number.

The Ministry of Information and Communications (2017). Circular No. 47/2017/TT-BTTTT dated December 29, 2017 which stipulates the promotional limit for the terrestrial mobile 
information services.

Government (2011). Decree No. 25/2011/ND-CP dated April 06, 2011 which stipulates detail and guidance for the implementation of some articles of Law on Telecommunications.

Authority of Information and Communication Technology Quality Control (2011). National technical regulation on quality of the terrestrial mobile telecommunications service QCVN 36: 2011/BTTTT.

Duong, T. T., \& Nguyen, H. B. (2011). Service quality of mobile phone networks in Nha Trang City. Scientific Journal, 19, 109-117.

Dinh B. H. A., \& To, N. H. K. (2017). Scientific research in socio-economy and guidelines for writing essay. Ho Chi Minh City Economic Publishing House, Ho Chi Minh

Dinh, K. (2015). Basic Econometric Curriculum (Theory and Exercises). University of Finance - Marketing.

Dinh, K. (2016). A set of lecture notes on econometric application with Eviews software. Advanced program in quantitative analysis, University of Finance - Marketing.

Huu, T. (2018). Network operators in the new war to gain market share. https://baodautu.vn/nha-mang-vao-cuoc-chien-moi-gianh-thi-phan-d83732.html

Nguyen, T. M. T. (2006). Service quality, satisfaction, and loyalty of supermarket customers in Ho Chi Minh City. Science and Technology Development Journal, 19(10), 57-70.

Pham, D. K., \& Bui, N. H. (2007). A research of customers' loyalty for mobile information services in Ho Chi Minh City market. Information Technology and Communications Journal, term 1 in February.

Kotler, P., Wong, V., Saunders, J., \& Armstrong, G. (2005). Principles of Marketing (4 ${ }^{\text {th }}$ European edition), Prentice Hall.

\section{Copyright Disclaimer}

Copyright for this article is retained by the author(s), with first publication rights granted to the journal.

This is an open-access article distributed under the terms and conditions of the Creative Commons Attribution license (http://creativecommons.org/licenses/by/3.0/). 